\title{
Feed and Weed: A Philosophy Of Book Selection
}

By PHILIP M. BENJAMIN

$\mathrm{H}$ ORTICULTURALLY, we could have a garden club brunch, romping through the analogies of book stacks to espaliered allées, and persuade ourselves to be reincarnations of Horace Walpole, lover of books and gardens. But the commercial slogan of "Feed and Weed" will bring us nearer to earth in dealing with the very practical, everyday problems of maintaining a well-used book collection, and give, hopefully, to the old, familiar and worn truisms of book selection a fresh pertinence, a basic and workable philosophy of action.

May $I$ indicate from the start that this paper is not a manual on book selection and readers' services, but some consideration of a "way" we can approach these tasks. My purpose will be achieved if, when I am finished, the reader will have found basic ideas that will make his own selection and use of books more constructive, meaningful and consistent.

The professional literature is full of suggestive devices, often helpful and applicable to one's individual situation; but such patchwork thinking on the matter seldom creates a strong, unified set of principles. We are here standing back from the procedures involved with the hope of seeing more clearly the result. If, in reviewing these procedures, we can evolve a consistency of purpose, we are more likely to derive a philosophy that will strengthen the quality of the collection and thus enhance its use. In short, I hope to stand somewhere midway of abstract theory and practical instruction.

We need, first, to agree upon circumstances upon which we can base our discussion. I am thinking in terms of col-
Mr. Benjamin is Librarian, Allegheny College, Meadville, Pennsylvania.

lege libraries with a book count from thirty thousand to three hundred thousand titles, with an average yearly acquisitions program of one thousand to four thousand titles. Any substantial count of duplicates for reserve, or for other purposes, should be deducted from the total holdings. The inclusion of regular acquisitions on standing orders, or in series, is not reconsidered beyond the original decision to acquire such titles. We shall explore methods of selection, but $\mathrm{I}$ am assuming that our librarian has as a major responsibility the development of the collection. For this reason I have indicated three hundred thousand volumes as our maximum size, presuming that such a collection in general will be maintained in a single building. If we have substantial departmental libraries, or even of necessity must house our collections in decentralized areas, such circumstances can definitely affect a philosophy of book selection. I stop short of the university library because here frequently there are aspects beyond our concern, such as resources for research for advanced degrees, or areas of highly specialized disciplines peculiar to the individual university. Such diversity involves delegation of authority. There may be found in this paper, nevertheless, ideas expressed that can be applied to this more complex problem.

But this distinction for our purpose between the undergraduate college and the university library implies two other 
aspects to be clarified. There is a definite relationship between open-stack policy and book selection. In most instances today the college library participates in the academic program by arranging a minimum of barriers between the undergraduate and the book. Ready access to the stacks is a learning process in itself. The limitation of stack privileges in the university library is defensible, particularly where decentralization provides departmental resources more readily at hand.

Allied to book selection, of course, is that of magazine and journal subscriptions. While I am omitting discussion on this point, we cannot finally judge the quality of any library without awareness of the resources thus available.

Let us assume, then, preliminary to expressing a philosophy of book selection, that the responsibility is one person's, a librarian who is thoroughly acquainted with his holdings; and, within the administration of his college, in a position to be cognizant of the institution's philosophy of education. These are prerequisites to constructive thinking.

A philosophy of book selection, then, first must be consistent with the basic philosophy of education sustained by the college. One should not labor so obvious a point, except to note that it affirms the important role of the library in any educational program. In contrast to the departmental laboratory, workshop, or clinic, the library must serve the entire college, academically and extracurricularly as well. A recognition of this truism supports the administrative significance of the librarian. It is not enough that his book collection serve the individual departments; too often this is responsible for the imbalance of the collection. By appointment the librarian, like the deans, is directly responsible to the president, and he should share in the top administrative discussions of policy. At the same time he is a close ad- junct to department heads, and needs to be in closer touch with individual faculty chairmen than that arising merely from association with the dean of the faculty.

Wherever the educational philosophy is clearly defined, the librarian can strengthen the united effort as it is passed down from president to instructor. In its formulation, one asks such questions as: Are we committed to a program emphasizing the total development of the undergraduate, in and out of the classroom? Are we a college highly specializing in the arts (or in the sciences) but not unmindful of valuable allied interests? Have we, by inheritance, accumulation, or emphasis, collections peculiar to our institution that need support and further development to insure their maximum use? Are we alert to trends and prepared to judge those of ephemeral and those of lasting interest and value? In the development of new areas of subject fields are we prepared to calculate the financial needs of the library as well as that of instruction? The answers to questions of this kind propound the educational philosophy of the college, and give unity to its achievement. Thoroughly acquainted with his collection, the librarian can present both the needs and the resources to the policymaking body.

The task of book selection solely by the librarian is an insuperable one, and undesirable as well. However successfully the mechanical selection of titles may be geared to the annual budget, it usually remains impersonal and wasteful. This is not the occasion to harp on the educational training of the librarian, except to point up the value of the subject disciplines over the general elementary background. Such textbooks as Lester Asheim's The Humanities and the Library are useful but by no means take the place of extensive study in a subject field, which trains the student in scholarly methods as well as resources. As a 
librarian, he then approaches fields other than his own with some appreciation of the kind of resources needed at various levels of study.

The librarian's cooperation with faculty departmental chairmen is mutually beneficial. Let us assume that our librarian is well versed and trained in politics, in chemistry, in literature, or in history. The collaboration with the faculty in any one of these areas in which he may approach their equal makes him more adept at accepting the counsel and suggestion in those areas in which he is clearly less informed but recognizes a manner of approach. Whatever the condition of the collection when the librarian undertakes a program of selection in specific areas, there must be a beginning, when department chairmen and librarian take stock of their resources and start strengthening it. In his own areas he can readily take the initiative; in other areas he must learn from his colleagues.

There is no point in rigid procedure here, so long as the selection is a simple and prompt one, where needs are anticipated and immediately filled. The varying percentage between titles selected by the librarian and by the professor will soon indicate the proficiency and preoccupation of each.

But unless the faculty are made aware of the resources and needs, unless they have the initial concern with acquisitions in their subject areas, the value of the selection is jeopardized so far as it contributes to usefulness and return on the investment of cost, processing, and shelf space. All of this is directly allied to putting the total educational policy of the college in action, and results in a healthy cooperation between faculty and library staff. But here I am pointing towards a philosophy of use.

Acquisitions recommended by the changing body of undergraduates seldom have marked significance, but should be considered by the librarian in maintaining his collection, especially where the open-stack policy prevails. For, even assuming that librarian and faculty have a good working understanding, the requests of the alert student, well motivated to individual searching by his instructor, may point out needs that have been overlooked. In addition, there is the whole area of extracurricular reading that must be supported in an attractive and satisfying book collection. Therefore the librarian finds his association with the dean of students and student life itself a valuable indicator of needs. In this way, the wise selection paves the road from curricular needs to the true breadth of interest which can be one of the most valuable attitudes cultivated in college. Here, perhaps, the librarian puts his philosophy of book selection to its greatest test, in maintaining a well-balanced collection.

At this point the reverse of selection plays a most important role and must be approached as philosophically. But when one has his principles and practices of book selection clearly in hand, he can proceed boldly upon a program of discarding. We all know how libraries accumulate until the problem of containment becomes a very real one. Temporary solutions only put off the inevitable awhile. But if we begin by understanding clearly the college's educational philosophy, we can with fair accuracy decide the optimal size of our collection, and proceed within these limitations. I shall not enumerate the many devices to be used, but concern myself a moment only with the weeding process itself. Worthless and superseded materials must be ruthlessly discarded; little-used materials must be placed in storage; historical landmarks gathered with exclusive judgment into small, permanent collections. These will result in a well-pruned, frequently reviewed collection on open shelves which will deprive no user of ready accessibility to the latest and the best, availability of all classical and standard works, a stimulating acquaint- 
ance with the historically valuable, and a sound protection from the great amount of ephemeral and worthless material. It is clear that rejection plays as important a role in any philosophy of book selection as does the choosing of materials to be acquired.

No philosophy of book selection is complete unless it considers the cooperation of the selector with his library staff. As the president informs his deans and department heads of his educational philosophy, thus reaching out to the faculty as a whole, so the librarian must share his philosophy of book selection with his departments within the library. As this gives him stature within the administrative organization, so it gives the staff of the library stature within the faculty.

He turns, then, first to his cataloger, or the head of his technical processes. Here the shelf list reflects the growth of the collection and the continuous problem of classification. As the faculty chairmen suggest desiderata, so the cataloger can be alert to serious needs and replacements while at the same time he sees the necessity of reclassification. Just as the preparation of a detailed subject bibliography may be revealing, so a problem of reclassification may present a serious weakness. The process of weeding, both slow and tedious, as well as engrossing and exhilerating, often calls attention to reclassification needs.

And finally, we move into the area which validates any philosophy of book selection: the readers' services. The reference and the circulation librarians are the most conscious of patrons' demands, and we cannot fail them. Again, the requests to them often reach beyond the specialized departmental inquiry to a background where the strength of the basic reference materials is repeatedly tested. Circulation and reference librarians, in turn, like the faculty chairmen, must be a part of the book selector's collaborative efforts.

This is a philosophy of book selection. Much of what I have said, I am sure, is obvious and common practice. But it makes clear, I hope, the very real, personal element that goes into making such a philosophy, which is as it can only be, since books themselves have value only as they are read.

\section{Global Documentation Standards}

Representatives of eleven member nations of Technical Committee 46 of the International Organization for Standardization considered seven proposed global standards for documentation in a June meeting in Paris. The three United States members were assigned the drafting of a new introduction governing transliteration of Greek and Cyrillic characters. No action was taken to revise the full global recommendation on transliteration but such work may be included in the committee's long-range plans. Draft proposals for bibliographical references, indexing of publications, title leaves of a book, abbreviation of generic names in periodical titles, and of typical words in bibliographical references were approved by the committee. Ratification by the forty-six member nations is the next step.

France was assigned the task of the romanization of Chinese, and a working group on transliteration will draft a report on the principles of transliteration, including Japanese and Yiddish. 